\title{
Pitting Kinetics of 304 Stainless Steel Using ESPI Detection Technique
}

\author{
Wen-Ming Tian $\cdot$ Ying-Jun Ai $\cdot$ Song-Mei Li $\cdot$ Nan Du $\cdot$ Chao Ye
}

Received: 18 June 2014/Revised: 17 August 2014/Published online: 3 March 2015

(C) The Chinese Society for Metals and Springer-Verlag Berlin Heidelberg 2015

\begin{abstract}
The electronic speckle pattern interferometer was used to in situ monitor the pitting corrosion of 304 stainless steel at anodic polarization. The pitting current and pitting current density of a single pit were obtained. The pit growth was controlled by the corrosion products diffusion. The pit morphology was observed by a scanning electron microscope. The results showed that the pit was dish shaped, and the geometric parameters and pit growth time conformed to the function of $Y=A+B_{1} t+B_{2} t^{2}+B_{3} t^{3}$.
\end{abstract}

\section{KEY WORDS: Stainless steel; Corrosion; Electronic speckle pattern interferometry (ESPI); Pitting}

\section{Introduction}

Stainless steel is widely used in industry because of its good mechanical properties, good processability and excellent corrosion resistance. But it always suffers from pitting corrosion in a range of aggressive environments [1-5]. It was found that the most commonly aggressive ion is the chloride ion in many natural and industrial environments [6, 7]. Pitting is generally focused on a small area of metal surface. It always causes the device perforation and initiates stress corrosion cracks [8,9]. Pits are nucleated at the microscopic scale and always covered by corrosion products, thus pitting is one of the more destructive

Available online at http://link.springer.com/journal/40195

W.-M. Tian · S.-M. Li

School of Materials Science and Engineering, Beihang

University, Beijing 100191, China

e-mail: tianwenming.dhr@163.com

Y.-J. Ai · N. Du $(\square) \cdot$ C. Ye

National Defence Key Discipline Laboratory of Light Alloy

Processing Science and Technology Institute, Nanchang

Hangkong University, Nanchang 330063, China

e-mail: d_unan@sina.com and undetectable forms of corrosion in metals $[10,11]$. In order to predict and prevent pitting corrosion, the dynamics of pit growth are worth further research.

Pitting research is classified primarily into two categories. One mainly studies the changing rules of physical properties such as pitting sensitivity by electrochemical and acoustic emission methods [12-17]. The parameters of pitting sensitivity include pitting potential, pitting initiation time, critical pitting temperature and so on; these parameters can indicate the pitting occurrence tendency in thermodynamics. Another tends to study the growth behavior of a specific pit. This kind of research often obtains metal weight loss, pit diameter and depth by statistical methods [18-21]. But these methods are not suitable to study the growth dynamics of a single pit due to they cannot obtain pitting occurrence time and position precisely. Many researchers studied pit growth by microelectrode and obtained lots of meaningful results. It was obtained that the separated pitting current transients caused by pit nucleation and metastable propagation with electrodes of $50 \mu \mathrm{m}$ diameter [8,22-25]. The microelectrode focuses on microscale and is suitable to study the metastable pitting. But for stable pits (always with a large volume), the microelectrode may not be effective at all, because the stable pit diameter may be bigger than the 
microelectrode; they are able to ascertain the occurrence time of pits but without the occurrence position, namely the pitting current transients and the pits cannot correspond to each other. Tian et al. [26] studied the metastable pits by polarization and in situ three-dimensional video microscope and found that metastable pit was not hemispherical, but turned from cone shaped to dish shaped during pit propagation. But this method is still not suitable for stable pits, especially the pit with a large volume. Nobuyoshi Hara et al. [27, 28] studied the dissolution of MnS inclusions during pit initiation with electrochemical microcell and in situ high-resolution optical microscope. They found very meaningful result of the study for pit initiation that the pit was generated at the MnS/matrix boundary after the dissolution of $\mathrm{MnS}$ inclusions, and the pit grew deeply into the steel matrix and wrapped beneath the inclusion. The scanning microelectrode, scanning probe microscope and Kelvin probe were introduced to study pitting corrosion in recent years and obtained some significant results [29-31]. These techniques mainly study pit initiation and sensitive position of pitting in a microscale, but they are inefficient to obtain growth kinetics of the stable pits due to the randomness of pitting corrosion. The ESPI technique is able to in situ monitor pitting corrosion continuously with a high sensitivity. It provides an effective way to study a single stable pit growth at macroscale $[32,33]$.

ESPI is a kind of optical measurement method which is based on laser and optoelectronic techniques and digital image processing. The chief advantages of ESPI are whole field, fast, noncontacting, and especially sensitive in temporal and space resolution $[34,35]$. It has been recognized as a highly accurate method for measuring surface displacements and has been widely used for deformation measurement and nondestructive tests, such as monitoring tensile and vibration tests, three-dimensional strain measurement and diffusion measurement in biochemical engineering [34-40]. Detecting localized corrosion may be a new use of ESPI [41].

The ESPI can ascertain pits occurrence time and position, and the number of pits by monitoring corrosion products diffusion during pitting corrosion [42-44]. In this study, the potentiostatic polarization, ESPI and a scanning electron microscope (SEM) were used to investigate the pitting corrosion of 304 stainless steel in $3.5 \mathrm{wt} \% \mathrm{NaCl}$ solution. The growth kinetics of a single stable pit was obtained.

\section{Experimental}

\subsection{Schematic of ESPI}

In the ESPI test, a He-Ne laser beam was used and divided into two beams by a beam splitter. One beam is a reference and the other is an object beam. The object beam scatters in all directions when it is incident to the uncorroded metal surface. The interference between these coherent scattered beams results in a speckle pattern which is recorded by the CCD camera and saved as the first speckle pattern. What follows is a possible explanation of how the ESPI technique behaves in the pitting corrosion situation in this work. When the metal surface is encountering pitting corrosion, the corrosion products begin to form and diffuse into the electrolyte and then give rise to the concentration difference between the local electrolyte near the pit and the bulk electrolyte. These two electrolytes have different refraction indices. Thus, the object beam travels in the electrolyte near the pit and the bulk electrolyte at different velocities resulting in an optical path difference. This engenders changes of the speckle pattern near the pit. This pattern is also recorded by the CCD camera and saved as the second speckle pattern. An ESPI image is then formed after subtraction the second speckle image from the first one. When a pit initiates on the metal surface a bright speckle occurs on the ESPI image. One bright speckle corresponds to a pit. The luminance of the bright speckle on ESPI image possibly increases with the increasing concentration of the local electrolyte near the pit, due to the refraction index increases with the electrolyte concentration or as a result of the local increase in pit size.

The schematic diagram of the corrosion products causing bright speckles is shown in Fig. 1. If the pitting had not occurred, then the second speckle image when subtracted from the first will result in a dark image, since the two

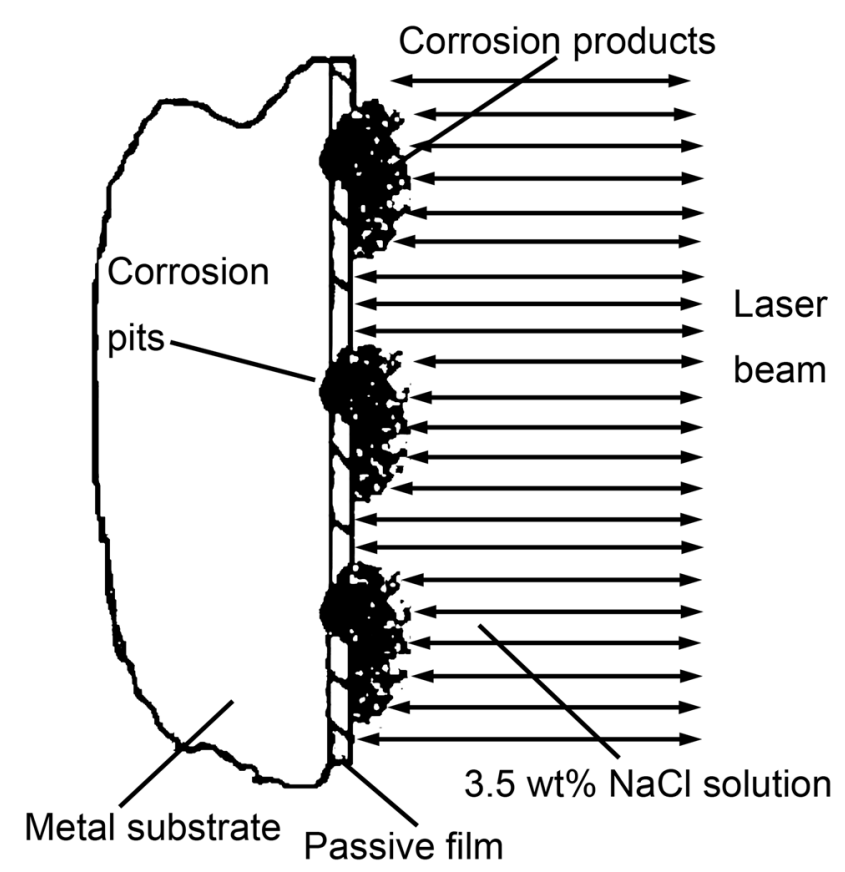

Fig. 1 Schematic diagram of the corrosion products causing bright speckles in $3.5 \mathrm{wt} \% \mathrm{NaCl}$ solution 
patterns have no difference. The main factors to possibly influence the speckle pattern include ions concentration in the local electrolyte near the pit, the shapes, layer thickness and volume of the local electrolyte near the pit and the layer thickness of bulk solution between specimen and CCD. All the factors are continuously changed during pit growth. In addition, the changes of pits bottom also can result in interference patterns, but the pits are covered by the soluble corrosion products, its interference pattern signals are mixed with the signals caused by local electrolyte near the pit. What is more, the sensitivity of ESPI is approximately $362 \mathrm{~nm}$ with $\mathrm{He}-\mathrm{Ne}$ laser light.

\subsection{Sample Preparation}

Specimens used in the study were made from 304 stainless steel, with a chemical composition (wt\%) of $\mathrm{C} 0.035, \mathrm{Si}$ 0.52 , Mn 1.18, P 0.036, S 0.026, Cr 17.59, Ni 8.03 and balance of Fe 72.6. 304 stainless steel was cut into cylinder of $10 \mathrm{~mm}$ in diameter to act as working electrode which was inlaid in phenolic resin. The electrical contact of the specimen was made from the rear by spot welding a copper lead on to the back of the specimen. The nonworking surface of the electrode was sealed with epoxy resin. The exposed surface of each electrode was finished by wet grinding with a series of emery papers from 400 to 1,200 grit number and then cleaned thoroughly with alcohol, acetone and deionized water in turn.

\subsection{Electrochemical and ESPI Experiments}

Electrochemical tests were carried out using a three-electrode electrochemical cell with a saturated calomel electrode (SCE) as a reference and a platinum sheet as the auxiliary electrode, applied potential was $0.35 V_{(\mathrm{SCE})}$. Before the electrochemical and pitting test, the electrodes were cathodically polarized for $5 \mathrm{~min}$ at $-1.3 V_{(\mathrm{SCE})}$ in order to remove the oxide film on the surface [26]. It was then immersed in test solution for $3 \mathrm{~h}$, so that the electrode surface would generate stable passive films. Electrochemical tests were provided by Autolab PGSTAT 302N. The electrochemical test system was mounted into an earthed Faraday cage to minimize interference from outside electrical signals. The ESPI system consisted of an electronic speckle measurement system, a He-Ne laser, a CCD camera and the digital image processing software. The schematic diagram of the test system is presented in Fig. 2. The optical devices and electrochemical devices were fixed on an anti-vibration platform. The QUANTA 200 SEM was used to observe pit morphologies. The test solution was $3.5 \mathrm{wt} \% \mathrm{NaCl}$ solution, prepared with deionized water, pure $\mathrm{NaCl}$ and without deoxygenation. The tests were performed at room temperature of $(20 \pm 2){ }^{\circ} \mathrm{C}$.

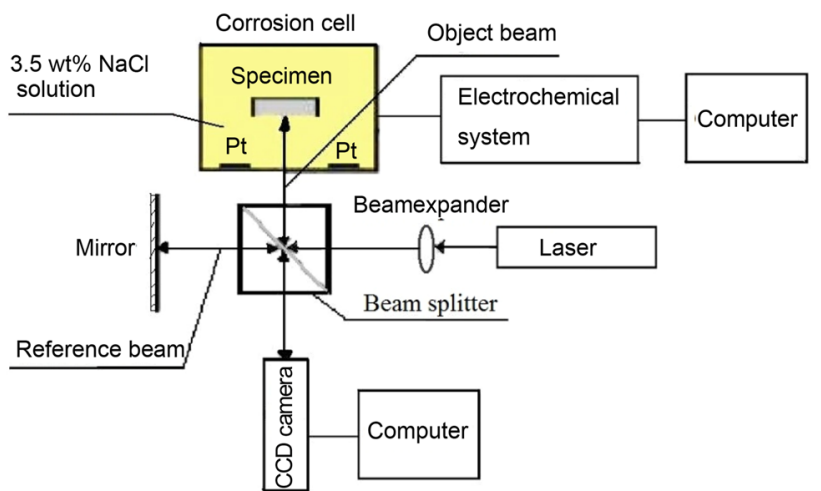

Fig. 2 Schematic diagram of the ESPI test system

\section{Results and Discussion}

\subsection{ESPI Monitoring with Potentiostatic Polarization}

When the applied potential was $0.35 V_{\text {(SCE) }}$, the current response on the electrode was measured, as shown in Fig. 3. In the plot, the pitting current is fairly stable with a value of 1.5-6 $\mu$ A during 0-26 s. It begins to increase after $26 \mathrm{~s}$, and increases in a series of fluctuations during 46-57 s. Finally, the current increases rapidly after $57 \mathrm{~s}$. The pitting current signals come from the whole electrode surface. The fluctuations are mainly caused by alternation of passivation and reactivation for pit surface, and the passivation is normally caused by rupture of deposited anodic salt films upon the pit surface [3-5, 11-13]. The corresponding ESPI images during polarization are treated by binarization technique to enhance the contrast of the

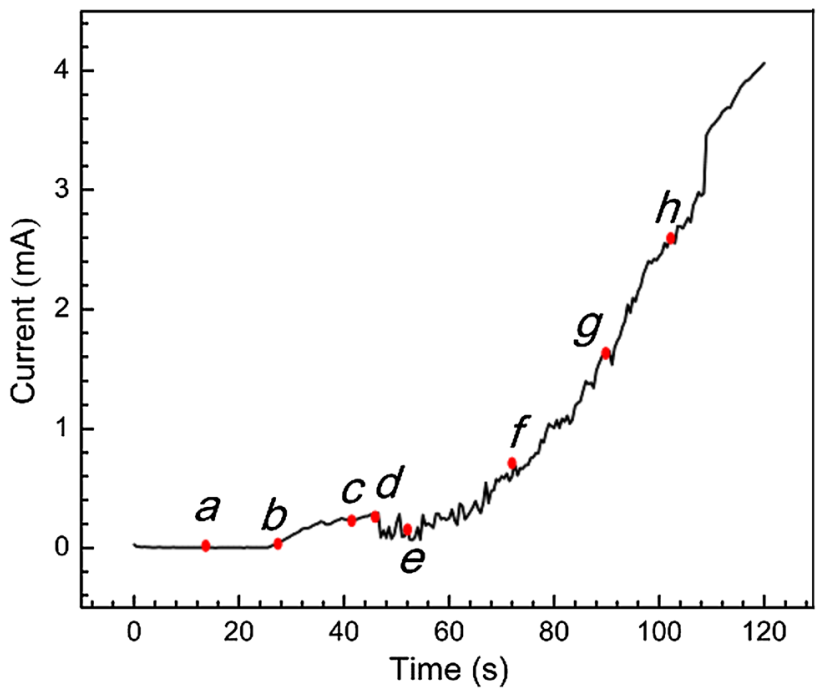

Fig. 3 Current-time curve of 304 stainless steel at $0.35 V_{(\mathrm{SCE})}$ polarization in $3.5 \mathrm{wt} \% \mathrm{NaCl}$ solution, pits $a-h$ indicate the occurrence time of speckles $A-H$ (as shown in the following Fig. 4) and the corresponding current 

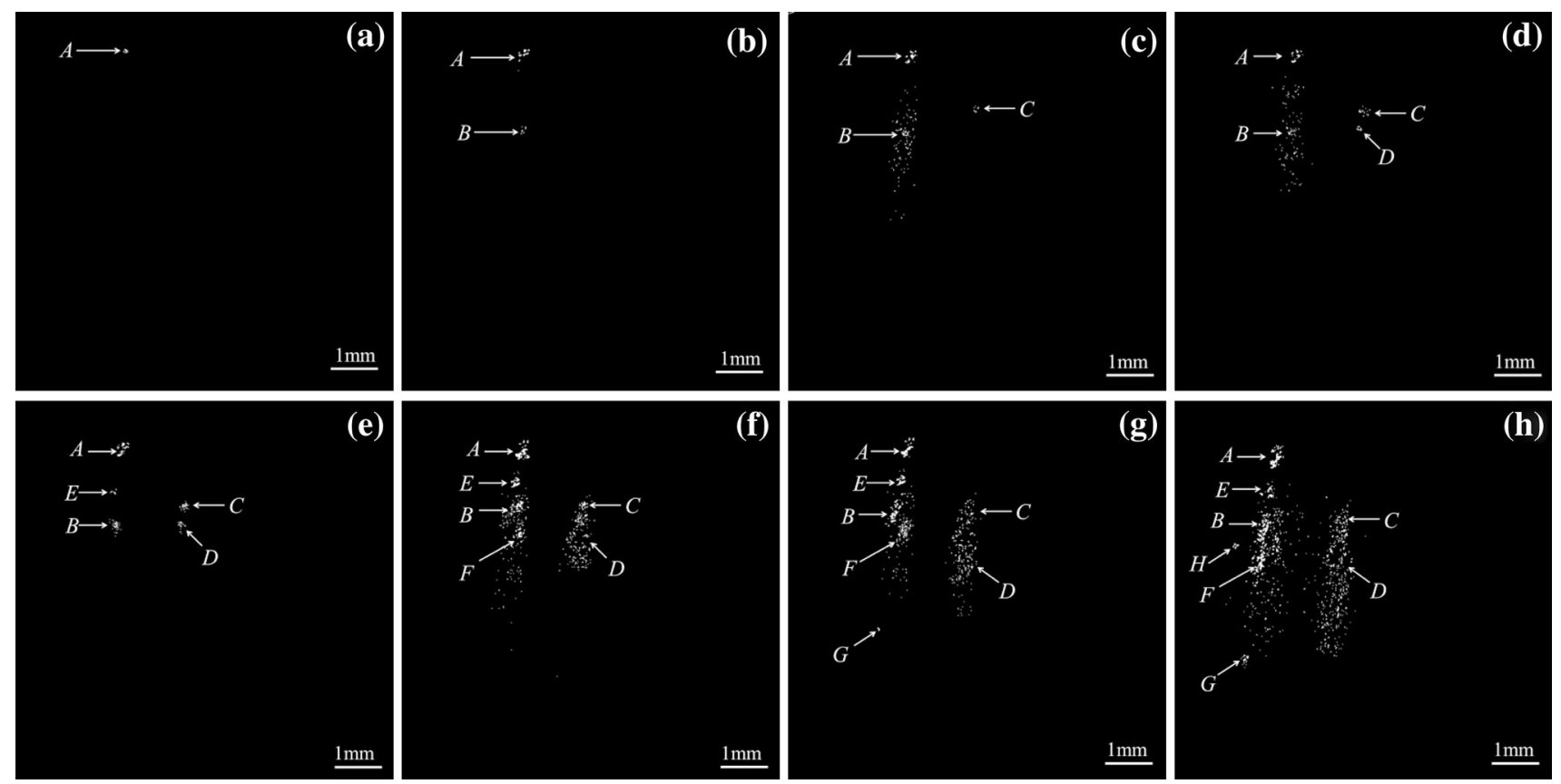

Fig. 4 ESPI images collected at different time when speckles occurred: a 14 s; b 27 s; c 41 s; d 45 s; e 52 s; f 72 s; g 90 s; h102 s

speckles and background, as shown in Fig. 4. The points $a$ to $h$ on the current-time curve (Fig. 3) indicate the occurrence time of bright speckles $A$ to $H$ on the ESPI images (Fig. 4), correspondingly. The positions of pits $A_{\mathrm{p}}$ to $H_{\mathrm{p}}$ on the electrode correspond to the positions of speckles $A$ to $H$ on the ESPI images.

No speckle occurs at the beginning of polarization which indicates that no pit initiates on the electrode. The speckle $A$ occurs on ESPI image at $14 \mathrm{~s}$ (Fig. 4a) suggesting that a pit is occurred on the electrode. At the same time, the current is just $1.648 \mu \mathrm{A}$ at point $a(14 \mathrm{~s})$ in Fig. 3, and it is not enough to ascertain the occurrence of pitting by observing the current-time curve. The passive current density of the electrode is very small, but the electrode's surface in this work is relatively very large. Therefore, the pitting current of an initiated pit is always obscured by the passive current of the whole electrode [5, 22-24]. However, the pitting occurrence can be ascertained by the ESPI images, since the ESPI is mainly detecting corrosion products produced by pit growth [42]. This indicates that ESPI has a better sensitivity to detect pitting corrosion. The speckle $B$ occurs at $27 \mathrm{~s}$, while the speckle $A$ is bigger and brighter than before (Fig. 4b). Speckle $C$ occurs at $41 \mathrm{~s}$, and speckles $A$ and $B$ grow continuously. It can be seen that speckles $A$ and $B$ come into a long tail at $41 \mathrm{~s}$, the long tail is actually the diffused corrosion products. In consequence of the corrosion products diffusion under gravity, the speckles are stretched. Speckle $D$ occurs nearby the speckle $C$ at 45 s. The two speckles fuse together to become a big speckle over time because of their immediate vicinity, but the two pits $\left(C_{\mathrm{p}}\right.$ and $\left.D_{\mathrm{p}}\right)$ can be distinguished by observing the surface of electrode. Similarly, the speckles $E, F, G$ and $H$ occur at 52, 72, 90 and 102 s, respectively. The occurrence time of speckles $A$ to $H$ and the corresponding pitting current are listed in Table 1.

The formation of pitting can be divided into four stages: (1) pitting nucleates on passive films or on the edge of inclusions; (2) pitting initiates beneath the passive films, and the microstructure of passive films changes at the same time; (3) metastable pitting occurs and turns to stable pitting; and (4) stable pitting propagates continuously [23, 31]. The adsorption of chloride ions causes the pitting nucleation in $\mathrm{NaCl}$ solution, and it is also the first and decisive step of passive films rupture. The researches on dynamics of chloride ions adsorption on passive films are relatively rare, because of the lack of in situ research methods. It is very difficult to investigate the rupture of passive films caused by chloride ions and also hard to estimate the reason of passive films destruction, since the passive films of stainless steel are very thin. It may be the adsorption of chloride ions on the passive films surface or the entrance of chloride ions into the passive films, however, may be both of them [9, 11, 18, 45]. The electrode keeps passivation and has an intact passive film at the beginning of the polarization. According to our experimental results [43], the pitting has already entered the third and fourth stages when the visible speckles occurred on ESPI images. The ESPI technique is mainly used to 
Table 1 Occurrence time of speckles $A-H$ and the corresponding current

\begin{tabular}{lcc}
\hline Speckle & $t(\mathrm{~s})$ & $I(\mu \mathrm{A})$ \\
\hline$A$ & 14 & 1.65 \\
$B$ & 27 & 31.1 \\
$C$ & 41 & 245 \\
$D$ & 45 & 278 \\
$E$ & 52 & 176 \\
$F$ & 72 & 601 \\
$G$ & 90 & 1,660 \\
$H$ & 102 & 2,610 \\
\hline
\end{tabular}

study the stable pit growth because the visible speckles just occur when the active growth pits reached a certain size.

\subsection{The Calculation of Pitting Current of a Single Pit}

When the speckle $A$ occurs on the ESPI image, the current $I_{1}$ is the pitting current $i_{a, n}$ of pit $A_{\mathrm{p}}$. Current $I_{2}$ is the sum of pitting current $i_{a, n}$ and $i_{b, n}$ of pits $A_{\mathrm{p}}$ and $B_{\mathrm{p}}$ when speckle $B$ occurs. Similarly, current $I_{3}$ is the sum of pitting current $i_{a, n}$, $i_{\mathrm{b}, n}$ and $i_{c, n}$ of pits $A_{\mathrm{p}}, B_{\mathrm{p}}$ and $C_{\mathrm{p}}$ when speckle $C$ occurs. The value of current $I_{t}$ can be obtained from Fig. 3 and Table 1, $t$ is the polarization time, $n$ is the growth time of pits (which can be got from the ESPI images). Then, the current expression can be represented as follows:

$I_{t}=i_{a, n}, \quad$ when $t=14-27 \mathrm{~s}$,

$I_{t}=i_{a, n}+i_{b, n}, \quad$ when $t=27-41 \mathrm{~s}$,

$I_{t}=i_{a, n}+i_{b, n}+i_{c, n}, \quad$ when $t=41-45 \mathrm{~s}$,

$I_{t}=i_{a, n}+i_{b, n}+i_{c, n}+i_{d, n}, \quad$ when $t=45-52 \mathrm{~s}$,

$I_{t}=i_{a, n}+i_{b, n}+i_{c, n}+i_{d, n}+i_{e, n}, \quad$ when $t=52-72 \mathrm{~s}$,

$I_{t}=i_{a, n}+i_{b, n}+i_{c, n}+i_{d, n}+i_{e, n}+i_{f, n}$,

when $t=72-90 \mathrm{~s}$,

$I_{t}=i_{a, n}+i_{b, n}+i_{c, n}+i_{d, n}+i_{e, n}+i_{f, n}+i_{g, n}$,

when $t=90-120 \mathrm{~s}$.

A previous work [44] has already shown that stable pits have basically the same growth speed at the same experimental conditions (especially the pits with a relatively big volume). So relationships are obtained as shown below:

$i_{a, 1}=i_{b, 1}=i_{c, 1}=\cdots=i_{g, 1}$,

$i_{a, 2}=i_{b, 2}=i_{c, 2}=\cdots=i_{g, 2}$,

$i_{a, 3}=i_{b, 3}=i_{c, 3}=\cdots=i_{g, 3}$.

The pitting current of a single stable pit can be calculated by Eqs. (1) to (10), and the result is shown in Fig. 5. The pitting current begins to increase at $11 \mathrm{~s}$ and

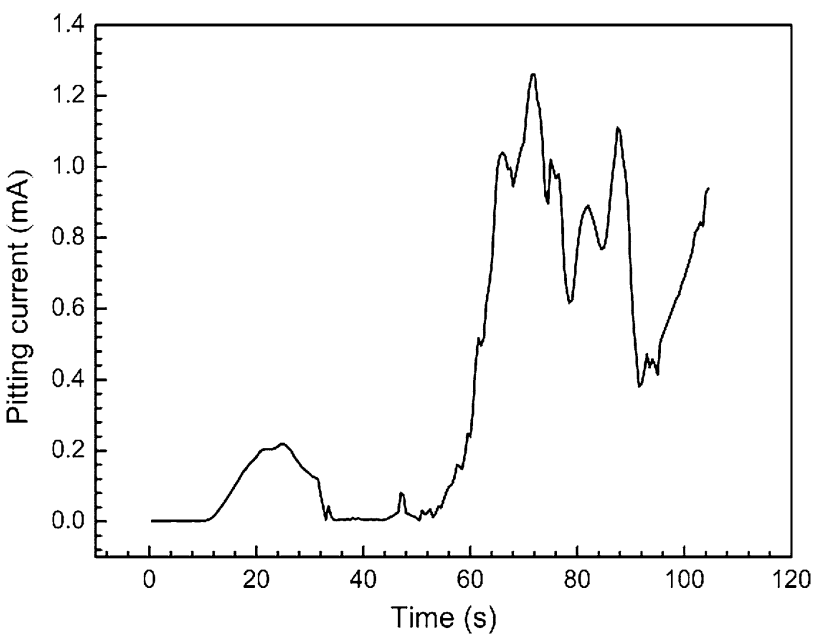

Fig. 5 Calculated pitting current of a single pit at $0.35 V_{(\mathrm{SCE})}$ polarization in $3.5 \mathrm{wt} \% \mathrm{NaCl}$ solution

slowly rises up until $27 \mathrm{~s}$ with an ultimate current of $185 \mu \mathrm{A}$. The pit repassivates after $27 \mathrm{~s}$, therefore the pitting current decreases during the period of 27-32 s, and the current fluctuates slightly during the period of $32-53 \mathrm{~s}$ with a tiny value. The fluctuations of pitting current are caused by the alternation of activation and passivation of the pit $[3-5,11-13]$. The autocatalysis of occluded cell leads to the rapid increase in pitting current after $53 \mathrm{~s}$. The occluded cell generates obvious concentration of metal and chloride ions, hydrolytic acidification of metal cations also occurs inside the pit. The random deposition or rupture of the deposited anodic salt films on the pit mouth or bottom changes the composition and concentration of the anolyte inside the pit $[5,8,22-25]$. Thus, the pitting current of a single pit fluctuates significantly after $75 \mathrm{~s}$.

\subsection{Geometric Parameters of Pits}

The SEM images of the various pits of 304 stainless steel are dish shaped at $0.35 V_{\text {(SCE) }}$ polarization in $3.5 \% \mathrm{NaCl}$ solution are shown in Fig. 6, the pits $A_{\mathrm{p}}$ to $H_{\mathrm{p}}$ correspond to the speckles $A$ to $H$, respectively. The occurrence and growth time of every pit can be obtained from the ESPI images. The geometric parameters of the pits with different growth time are shown in Fig. 7.

From Fig. 6, it can be seen that the geometry of the pit is dependent on the polarization potential. At lower applied potentials, the pits are cone shaped, while, as the potential increasing, the pits turn from cone shaped to dish shaped $[4,11,12,23]$. In this study, the $0.35 V_{(\mathrm{SCE})}$ is a relatively high potential, thus dish shaped pits are obtained. It can be concluded from Fig. 7 that the length, width and area of the pit increase with time. The geometric parameters conform to the function with time, as shown below: 

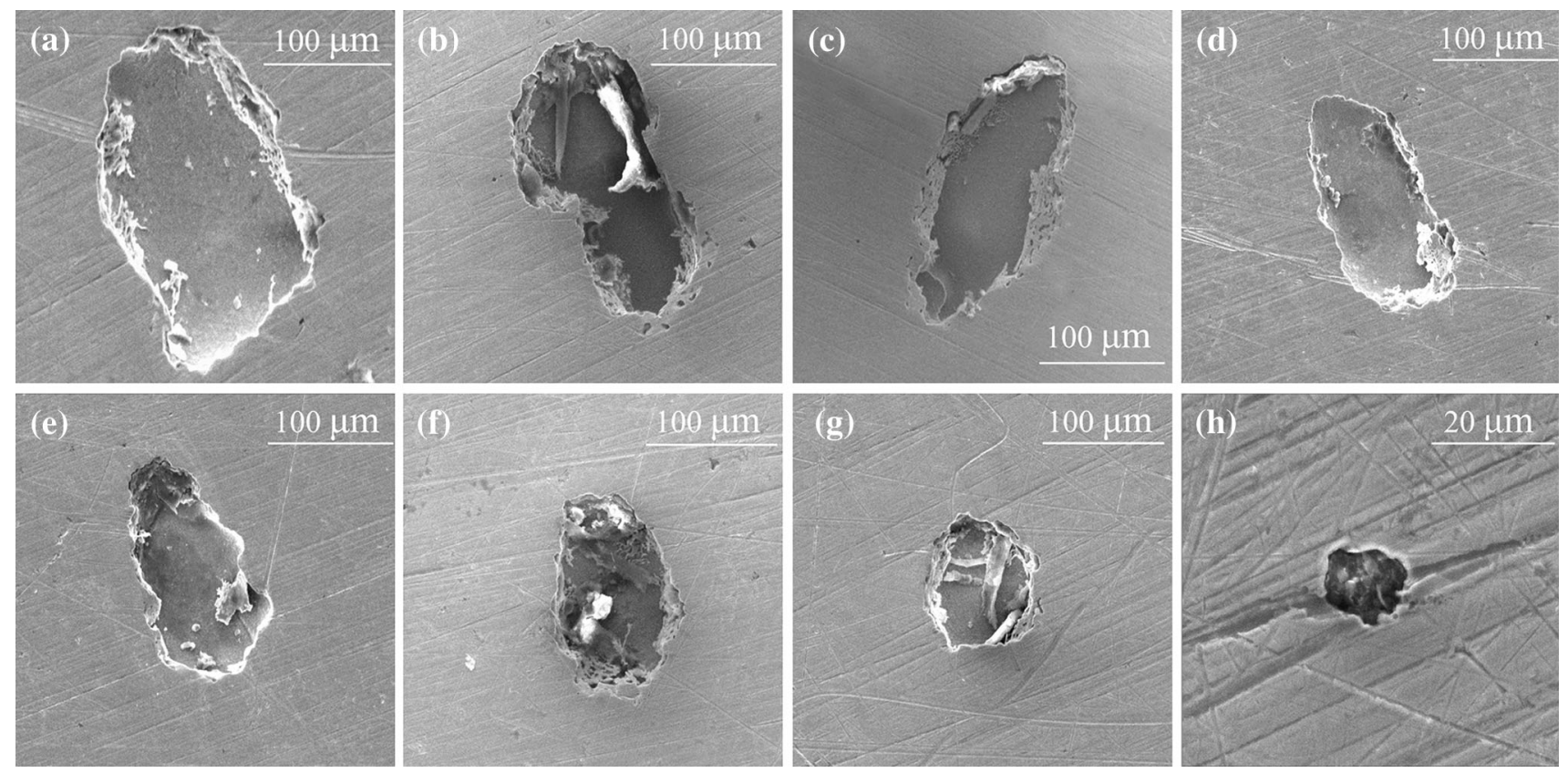

Fig. 6 SEM images of pits $A_{\mathrm{p}} \mathbf{a}, B_{\mathrm{p}} \mathbf{b}, C_{\mathrm{p}} \mathbf{c}, D_{\mathrm{p}} \mathbf{d}, E_{\mathrm{p}} \mathbf{e}, F_{\mathrm{p}} \mathbf{f}, G_{\mathrm{p}} \mathbf{g}, H_{\mathrm{p}} \mathbf{h}$, which correspond to the speckles $A-H$ in Fig. 4
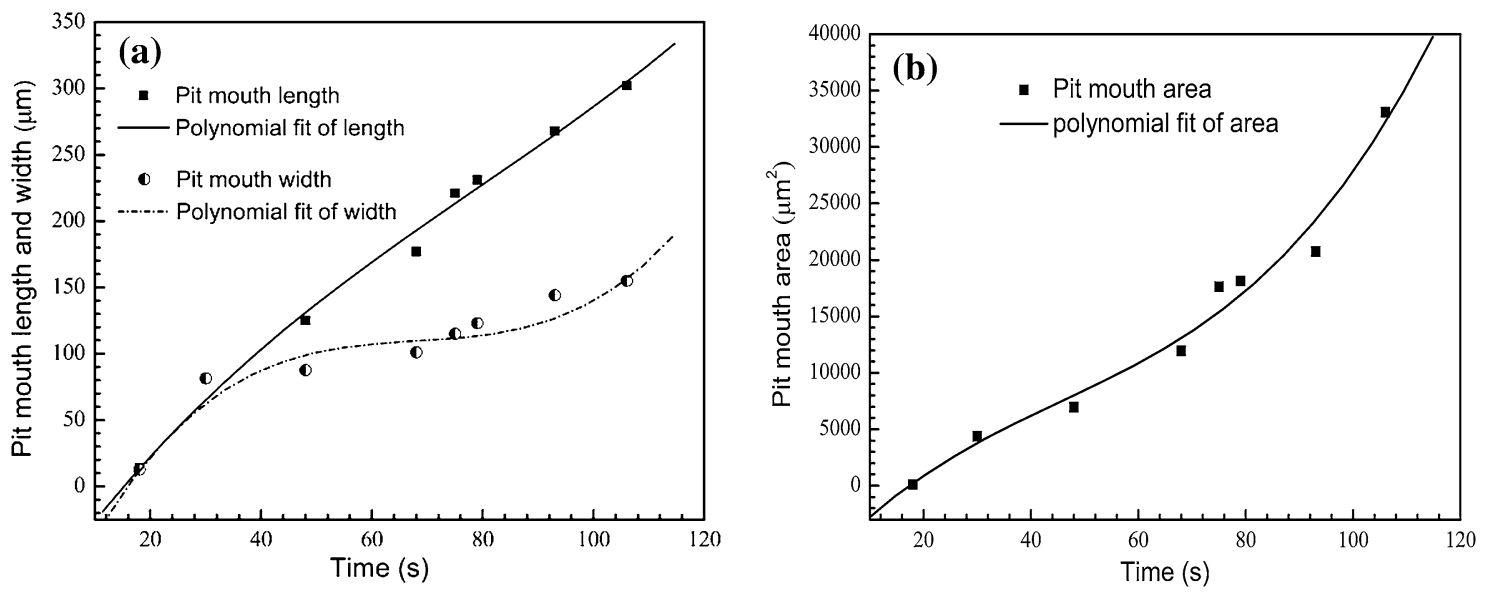

Fig. 7 Geometric parameters of pits with different growth time: a length and width of pit mouth; $\mathbf{b}$ area of pit mouth

Table 2 Values of $A, B_{1}, B_{2}$, and $B_{3}$ in Eq. (11) for different geometric parameters of pit mouth length $(L)$, pit mouth width $(W)$ and pit mouth area $(S)$, respectively

\begin{tabular}{lrrll}
\hline Parameter & \multicolumn{1}{l}{$A$} & \multicolumn{1}{l}{$B_{1}$} & \multicolumn{1}{l}{$B_{2}$} & \multicolumn{1}{l}{$B_{3}$} \\
\hline$L$ & -62.4107 & 5.0348 & -0.0262 & $1.0770 \mathrm{E}-4$ \\
$W$ & -100.5224 & 8.7260 & -0.1250 & $6.1841 \mathrm{E}-4$ \\
$S$ & -7504.9705 & 536.9803 & -6.8602 & 0.0752 \\
\hline
\end{tabular}

$Y=A+B_{1} t+B_{2} t^{2}+B_{3} t^{3}$

where $Y$ is the geometric parameter of pit and $t$ is the pit growth time. The values of $A, B_{1}, B_{2}$ and $B_{3}$ are listed in Table 2. According to the data shown in Fig. 7, the extension speed of pit mouth at different growth time can be obtained, as shown in Fig. 8. The length and width of pit mouth have basically the same extension speed during the period of 0-24 s, so the pit mouth is circular shaped at the beginning of pitting. But the extension speed of pit mouth length becomes faster than the pit mouth width after $24 \mathrm{~s}$, thus the pit mouth changes from circular shaped to oval shaped during pit stable growth. The metal dissolution rate of pit mouth is related to the rolling direction. Generally, for austenitic stainless steel, the metal dissolution is relatively rapid at the direction paralleled to the rolling direction [46-48]. Thus, the pit mouth length direction may parallel to the rolling direction. The extension speed of pit 

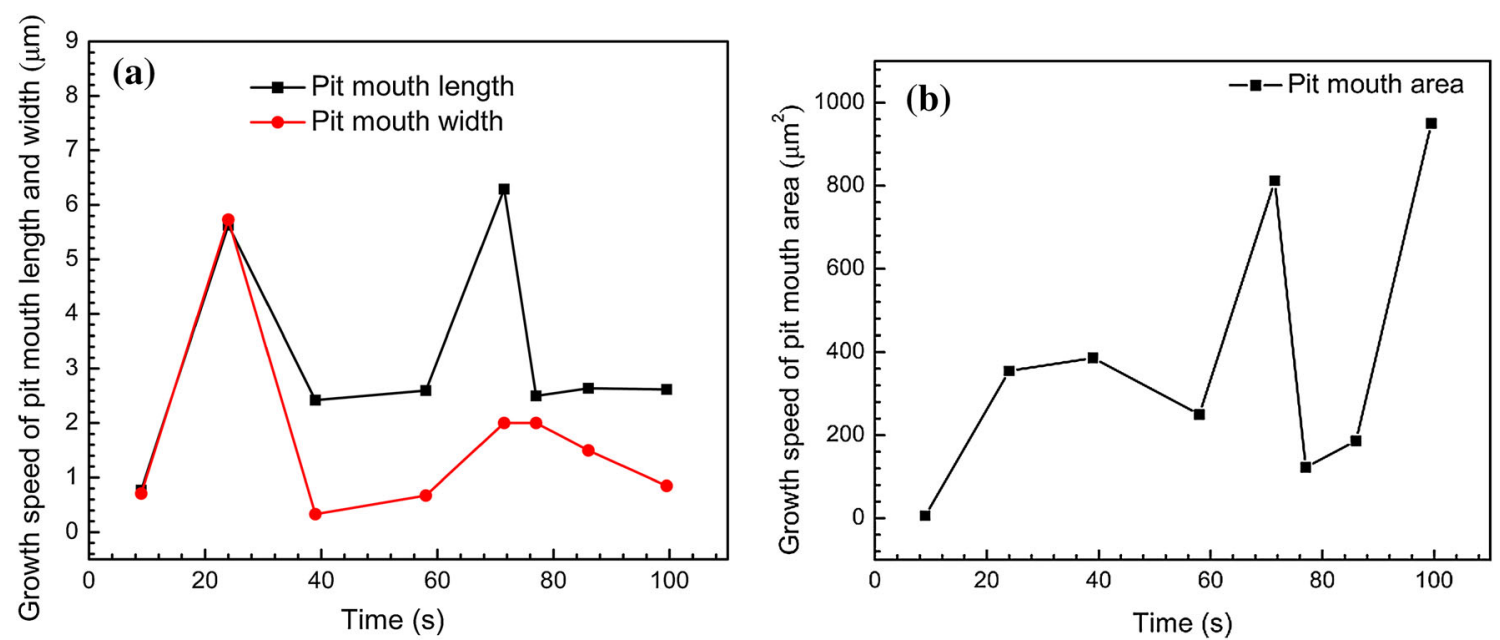

Fig. 8 Calculated growth rate of a pit mouth at different time: a growth rate of pit mouth length and width; $\mathbf{b}$ growth rate of pit mouth area

mouth area increases with time basically, but with a significant fluctuation.

By comparing the curves in Figs. 5, 8, similar trend is found: the extension speed of pit mouth increases or decreases correspondingly to the pitting current increasing or decreasing. This phenomenon can also confirm that stable pits have basically the same growth speed at the same experimental conditions.

\subsection{Pitting Current Density of a Single Pit}

Pitting current density of a single pit can be obtained by dividing pitting current by pit area. Figure 9 shows the pitting current density of a single pit. Pitting current density achieves a high value of $30 \mathrm{~A} / \mathrm{cm}^{2}$ at $18 \mathrm{~s}$. The pit can erodes quickly due to this high pitting current density at initial stage and forms a metal ions diffusion barrier to sustain the propagation of the pit $[49,50]$. This big pitting

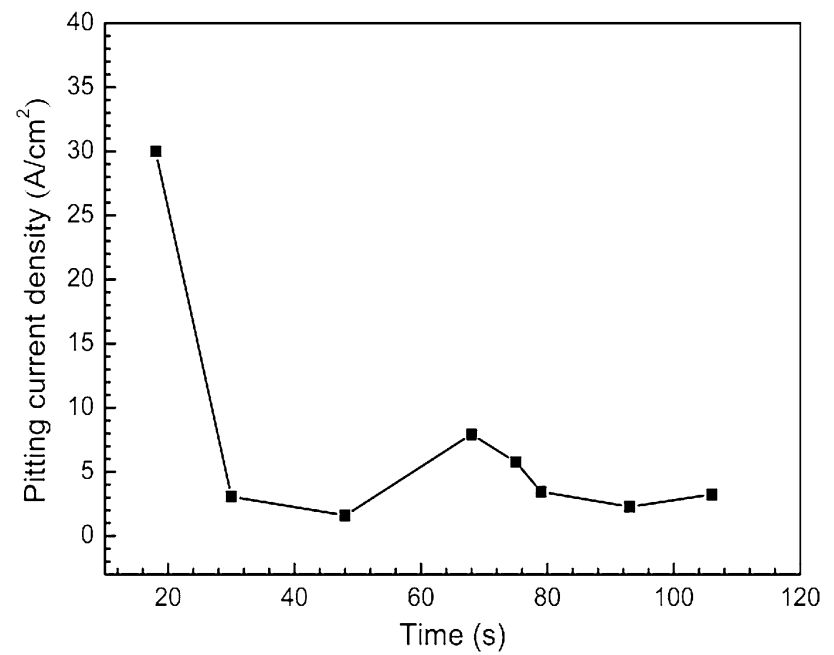

Fig. 9 Calculated pitting current density of a single stable pit at $0.35 V_{\text {(SCE) }}$ polarization in $3.5 \mathrm{wt} \% \mathrm{NaCl}$ solution current density makes the ir [the product of pitting current density $(i)$ and pit radius $(r)]$ to exceed the pit stability product $(3 \mathrm{~mA} / \mathrm{cm})[5,49]$, therefore, in this study, the pits are stably growing pits. The pitting current density decreases during 18-30 s and becomes stable with a value of 2-8 $\mathrm{A} / \mathrm{cm}^{2}$. It indicates that the pit growth is controlled by corrosion products diffusion $[5,8,22-25,49,50]$. After the initiation of the pit, at the edges of the pit, transport of metal ions into the bulk solution is relatively rapid, the local concentration falls below the critical value and repassivation occurs, in contrast, deeper into the pit cavity, active dissolution continues such that pit growth undercuts the passivated material and eventually breaks through the surface from beneath. Metal ions diffuse rapidly through the new hole, again causing the local concentration to fall and repassivation to occur at the edges [51-58], thus the

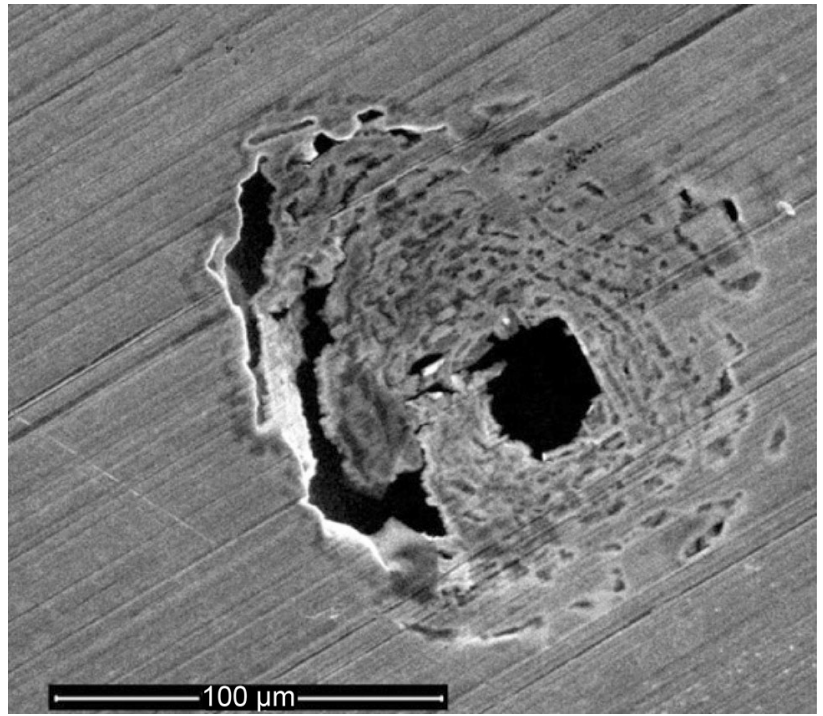

Fig. 10 SEM image of pit mouth lace cover at $0.35 V_{(\mathrm{SCE})}$ polarization in $3.5 \mathrm{wt} \% \mathrm{NaCl}$ solution 
porous lace cover is formed as shown in Fig. 10. The insoluble corrosion products such as $\mathrm{Fe}(\mathrm{OH})_{3}$ and $\mathrm{Fe}(\mathrm{OH})_{2}$ sometimes also deposit at the holes on the lace cover during pit stable propagation. The lace cover and deposited anodic salt films retard the exchange of inside and outside electrolyte of the pit, therefore the corrosion products diffusion becomes the control factor of the stable pit growth $[5,8,22-25,49,50]$. The random deposition and rupture of anodic salt films on the lace cover will cause fluctuations of pitting current density.

\section{Conclusions}

The ESPI technique appears to have higher sensitivity in detecting pitting corrosion than potentiostatic polarization. The stable pit of 304 stainless steel was dish shaped at $0.35 V_{\text {(SCE) }}$ polarization. The pit mouth geometric parameters and pit growth time conformed to the function of $Y=A+B_{1} t+B_{2} t^{2}+B_{3} t^{3}$. The pitting current density of a single pit could achieve a high value of $30 \mathrm{~A} / \mathrm{cm}^{2}$ at the initial stage of pitting and then kept at a stable value of $2-8 \mathrm{~A} / \mathrm{cm}^{2}$. The pit growth was controlled by corrosion products diffusion. The changes of ions concentration of anolyte in the pit would lead to the fluctuations of pitting current and pitting current density.

Acknowledgments This work was financially supported by the National Nature Science Foundation of China (No. 51071083).

\section{References}

[1] L. Xu, Y. Meng, Y. Shi, Y. Liu, Acta Metall. Sin. (Engl. Lett.) 26, 271 (2013)

[2] B. Wang, L. Zhang, Y. Su, Y. Xiao, J. Li, Acta Metall. Sin. (Engl. Lett.) 26, 581 (2013)

[3] L.Q. Guo, Y. Bai, B.Z. Xu, W. Pan, L.J. Qiao, Corros. Sci. 70, 140 (2013)

[4] H.S. Klapper, J. Goellner, A. Burkert, A. Hegn, Corros. Sci. 75, 239 (2013)

[5] P.C. Pistorius, G.T. Burstein, Corros. Sci. 36, 525 (1994)

[6] A. Parsapour, S.N. Khorasani, M.H. Fathi, Acta Metall. Sin. (Engl. Lett.) 26, 409 (2013)

[7] F. Sun, X. Li, F. Zhang, X. Cheng, C. Zhou, N. Wu, Y. Yin, J. Zhao, Acta Metall. Sin. (Engl. Lett.) 26, 257 (2013)

[8] G.T. Burstein, C. Liu, R.M. Souto, S.P. Vines, Corros. Eng. Sci. Technol. 39, 25 (2004)

[9] A.A. Younis, M.M.B. El-Sabbah, R. Holze, J. Solid State Electrochem. 16, 1033 (2012)

[10] H.B. Li, Z.H. Jiang, Y. Cao, Z.R. Zhang, J. Metall. Mater. 16, $517(2009)$

[11] Y. Kim, R.G. Buchheit, Electrochim. Acta 52, 2437 (2007)

[12] J. Gao, Y.M. Jiang, B. Deng, Z. Ge, J. Li, Electrochim. Acta 55, $4837(2010)$

[13] K. Darowicki, S. Krakowiak, P. Slepski, Electrochim. Acta 49(290), 9 (2004)

[14] M.G. Pujar, T. Anita, H. Shaikh, R.K. Dayal, H.S. Khatak, J. Mater. Eng. Perform. 16, 494 (2007)
[15] J.L. Xu, T. Sun, L.H. Zhang, J. Li, Y.M. Jiang, J. Mater. Sci. Technol. 28, 474 (2012)

[16] K. Darowicki, A. Mirakowski, S. Krakowiak, Corros. Sci. 45, 1747 (2003)

[17] J. Xu, X.Q. Wu, E.H. Han, Corros. Sci. 53, 1537 (2011)

[18] D.M. Sun, Y.M. Jiang, Y. Tang, Q.W. Xiang, Electrochim. Acta 54, 1558 (2009)

[19] Z.L. Tang, J. Soc. Corros. Protect. China 18, 241 (1998). (in Chinese)

[20] G.T. Gaudet, W.T. Mo, T.A. Hatton, J.W. Tester, J. Tilly, H.S. Isaacs, R.C. Newman, AIChE J. 32, 949 (1986)

[21] N.J. Laycock, S.P. White, J. Electrochem. Soc. 148, 264 (2001)

[22] G.T. Burstein, R.M. Souto, C. Liu, S.P. Vines, Corros. Mater. 29, 1 (2004)

[23] P.C. Pistorius, G.T. Burstein, Corros. Sci. 33, 1885 (1992)

[24] G.T. Burstein, S.P. Vines, J. Electrochem. Soc. 148, 504 (2001)

[25] K. Sasaki, G.T. Burstein, Corros. Sci. 49, 92 (2007)

[26] W. Tian, N. Du, S. Li, S. Chen, Q. Wu, Corros. Sci. 85, 372 (2014)

[27] I. Muto, Y. Izumiyama, M. Hara, J. Electrochem. Soc. 154, 439 (2007)

[28] A. Chiba, I. Muto, Y. Sugawara, N. Hara, J. Electrochem. Soc. 159, 341 (2007)

[29] R.E. Williford, C.F. Windisch, R.H. Jones, Mater. Sci. Eng. 288, 54 (2000)

[30] F.A. Martin, C. Bataillon, J. Cousty, Corros. Sci. 50, 84 (2008)

[31] M. Li, L.Q. Guo, L.J. Qiao, Y. Bai, Corros. Sci. 60, 76 (2012)

[32] D. Mayorga-Cruz, P.A. Márquez-Aguilar, O. Sarmiento-Martínez, J. Uruchurtu-Chavarín, Opt. Laser Eng. 45, 140 (2007)

[33] R.K. Singh Raman, R. Bayle, Eng. Fail. Anal. 13, 1051 (2006)

[34] J. Petit, G. Montay, M. Francois, Strain 47, 363 (2011)

[35] A. Martínez, J.A. Rayas, R. Cordero, Opt. Commun. 262, 8 (2006)

[36] R. Suterio, A. Albertazzi, F.K. Amaral, J. Strain Anal. 41, 517 (2006)

[37] A. Martínez, J.A. Rayas, R. Rodríguez-Vera, H.J. Puga, Appl. Opt. 43, 4652 (2004)

[38] A. Axelsson, M. Marucci, Opt. Laser Eng. 46, 865 (2008)

[39] V. Bavigadda, R. Jallapuram, E. Mihaylova, V. Toal, Opt. Lett. 35, 3273 (2010)

[40] G. Jin, S. Tang, Opt. Eng. 31, 857 (1992)

[41] F. Jin, F.P. Chiang, Res. Nondestruct. Eval. 10, 63 (1998)

[42] M.F. Wang, X.G. Li, N. Du, Y.Z. Huang, A. Korsunsky, Electrochem. Commun. 10, 1000 (2008)

[43] N. Du, G. Liu, Q. Zhao, Front. Mater. Sci. China 2, 326 (2008)

[44] N. Du, W.M. Tian, Q. Zhao, S.B. Chen, Acta Metall. Sin. 48, 807 (2012). (in Chinese)

[45] V.A. Marichev, Electrochim. Acta 53, 6304 (2008)

[46] L. Peguet, B. Malki, B. Baroux, Corros. Sci. 51, 493 (2009)

[47] A. Shahryari, J.A. Szpunar, S. Omanovic, Corros. Sci. 51, 677 (2009)

[48] L. Peguet, B. Malki, B. Baroux, Corros. Sci. 49, 1933 (2007)

[49] P.C. Pistorius, G.T. Burstein, Philos. Trans. R. Soc. 341, 531 (1992)

[50] G.T. Burstein, P.C. Pistorius, Corros. Sci. 37, 380 (1995)

[51] N.J. Laycock, J. Stewart, R.C. Newman, Corros. Sci. 39, 1791 (1997)

[52] R.C. Newman, Corros. Sci. 37, 527 (1995)

[53] P. Ernst, R.C. Newman, Corros. Sci. 44, 927 (2002)

[54] M.H. Moayed, R.C. Newman, Corros. Sci. 48, 1004 (2006)

[55] P. Ernst, R.C. Newman, Corros. Sci. 44, 943 (2002)

[56] P. Ernst, N.J. Laycock, M.H. Moayed, R.C. Newman, Corros. Sci. 39, 1133 (1997)

[57] P. Ernst, R.C. Newman, Corros. Sci. 49, 3705 (2007)

[58] W. Tian, S. Li, N. Du, S. Chen, Q. Wu, Corros. Sci. 93, 242 (2015) 